\title{
Efficacy and safety of gemcitabine plus capecitabine in the treatment of advanced or metastatic pancreatic cancer: a systematic review and meta-analysis
}

\author{
Bo-Ya Xiao" ${ }^{1}$ Bi-Cheng Wang ${ }^{2}$, Guo-He Lin ${ }^{3}$, Peng-Cheng Li ${ }^{1}$ \\ ${ }^{1}$ Shanghai Eastern Hepatobiliary Surgery Hospital, Shanghai, China; ${ }^{2}$ Cancer Center, Union Hospital, Tongji Medical College, Huazhong University \\ of Science and Technology, Wuhan, China; ${ }^{3}$ Department of Oncology, the Second Affiliated Hospital of Anhui Medical University, Hefei, China \\ Contributions: (I) Conception and design: BC Wang, BY Xiao; (II) Administrative support: None; (III) Provision of study materials or patients: None; \\ (IV) Collection and assembly of data: BC Wang, BY Xiao; (V) Data analysis and interpretation: BC Wang, BY Xiao; (VI) Manuscript writing: All \\ authors; (VII) Final approval of manuscript: All authors. \\ Correspondence to: Bi-Cheng Wang, MD. Cancer Center, Union Hospital, Tongji Medical College, Huazhong University of Science and Technology, \\ 1277 Jiefang Avenue, Wuhan 430022, China. Email: bcsnowell@163.com.
}

Background: Gemcitabine combined the oral fluoropyrimidine capecitabine (GemCap) is an active
antitumor therapy in the treatment of advanced or metastatic pancreatic cancer, and has been shown
potential synergistic activity in previous clinical trials. In this study, we sought to systematically review and
synthesize the efficacy and safety of GemCap in the treatment of advanced or metastatic pancreatic cancer.
Methods: A systematic review was performed through PubMed, Cochrane Library, EMBASE, and Web of
Science databases up to Jul 10, 2019 to identify clinical trials that included advanced or metastatic pancreatic
cancer patients treated with GemCap. Data of overall survival (OS), progression-free survival (PFS), 1-year
survival rate, objective response rate (ORR), disease control rate (DCR) and adverse events were extracted
and meta-analyzed. Results: Fifteen studies were identified for systematic review, of which 13 were included in the metaanalysis. In comparison with Gem monotherapy, the pooled hazard ratios (HR) of GemCap treatment for OS and PFS were 0.85 (95\% CI: 0.75-0.95, P=0.007) and 0.80 (95\% CI: 0.72-1.04, P=0.0002). The pooled 1-year survival rate, ORR and DCR of GemCap were, respectively, 33.1\% (95\% CI: 28.7-37.5), 22.9\% (95\% CI: 17.6-28.3) and 65.7\% (95\% CI: 56.7-74.8). GemCap combination therapy showed significantly higher ORR (OR: 1.98, 95\% CI: 1.34-2.67, P=0.0003) and DCR (OR: 1.41, 95\% CI: 1.05$1.88, \mathrm{P}=0.02$ ) compared to Gem monotherapy. The most common grade $\geq 3$ hematological toxicities in patients treated with GemCap combination therapy were neutropenia (19.7\%), leucocytopenia (7.9\%) and anemia (4.9\%). The most common grade $\geq 3$ non-hematological toxicities were hand-foot syndrome (6.3\%), fatigue $(5.7 \%)$ and nausea $(4.8 \%)$.

Conclusions: GemCap combination therapy had an encouraging activity and might be a better treatment strategy compared with Gem alone in the first-line treatment for patients with advanced or metastatic pancreatic cancer.

Keywords: Gemcitabine; capecitabine; combination chemotherapy; pancreatic cancer; meta-analysis

Submitted Jan 08, 2020. Accepted for publication May 21, 2020.

doi: 10.21037/apm-20-45

View this article at: http://dx.doi.org/10.21037/apm-20-45 


\section{Introduction}

The outcomes of patients with locally advanced or metastatic pancreatic cancer remain poor (1). The median overall survival (OS) for those with stage IV disease is less than 12 months $(2,3)$, even when patients are treated with systemic chemotherapies or combination chemotherapies $(4,5)$.

Since 1997, the single-agent gemcitabine (Gem) has been a standard-of-care first-line treatment for advanced pancreatic cancer, with a significant survival benefit and a safety profile compared to 5-fluorouracil monotherapy (6). Subsequently, various Gem combinations with different chemotherapeutic regimens, comprising paclitaxel, capecitabine (Cap), and platinum, have been applied in advanced pancreatic cancer patients $(7,8)$. MPACT study showed that the combination chemotherapy regimen, Gem/nab-paclitaxel, achieved a higher response rate and longer median overall survival (OS) than Gem (3). Another randomized controlled clinical trial reported that Gem plus oxaliplatin, compared with Gem alone, resulted in an improved objective response rate (ORR) and progressionfree survival (PFS) (9). However, in an Eastern Cooperative Oncology Group trial, Gem combined with oxaliplatin failed to improve OS in advanced pancreatic cancer patients (10). Additional combination chemotherapy regimens have also become the treatment strategies for advanced pancreatic cancer. In 2011, a cornerstone study in exploring advanced or metastatic pancreatic cancer chemotherapy was published by Conroy (2). The FOLFIRINOX (a combination of fluorouracil, leucovorin, oxaliplatin, and irinotecan) treatments was associated with a significant improvement in OS versus Gem monotherapy (2). Owing to the greater toxicities, the adoption of FOLFIRINOX for patients with good performance status $(11,12)$. Furthermore, although FOLFIRINOX was associated with slightly longer median $\mathrm{OS}$ in relative to Gem-based combination chemotherapy, the difference was not statistically significant (13).

Cap is an oral fluoropyrimidine that has been approved for the treatment of various cancer types $(14,15)$. The improved safety and similar benefit of Cap compared with intravenous fluorouracil and the convenience of oral administration make Cap an attractive treatment option in advance pancreatic cancer $(4,16)$. Cap monotherapy had been demonstrated similar clinical activity compared with single-agent Gem in advanced pancreatic cancer $(6,17)$.

The combination of Gem and Cap (GemCap) has been shown promising antitumor activity in phase I and II clinical trials in patients with advanced pancreatic cancer (18-21).
Although GemCap was associated with a trend toward improved OS but failed to improve OS at a statistically significant level compared with Gem alone (4,16,22). At the moment, both GemCap combination therapy and Gem monotherapy are the general treatment strategies for advanced or metastatic pancreatic cancer in our hospital. We have noticed that GemCap combination therapy might be superior to Gem monotherapy, however, published clinical data remain controversial and could not directly support this hypothesis. Therefore, associated clinical trials published up to 2019 were collected to assess the benefit and risk of GemCap combination chemotherapy in patients with advanced or metastatic pancreatic cancer. Here, we systematically reviewed the reported clinical trials and performed a meta-analysis of the available data regarding GemCap therapy on survival estimates, tumor response rates, and tolerability. We conducted the meta-analysis following the Preferred Reporting Items for Systematic Reviews and Meta-analyses guideline (available at http:// dx.doi.org/10.21037/apm-20-45) (23).

\section{Methods}

\section{Search strategy}

A systematic literature search was performed in the electronic databases PubMed, Cochrane Library, Web of Science, and EMBASE. The last search was run on Jul 10, 2019. Search terms included: "advanced pancreatic cancer or advanced pancreatic adenocarcinoma or metastatic pancreatic cancer or metastatic pancreatic adenocarcinoma", "gemcitabine", "capecitabine", and "trial or clinical trial or randomized clinical trial or randomized controlled trial". Only articles written in English were assessed. The references of articles were searched for more eligible studies.

\section{Selection criteria}

Eligible studies included advanced or metastatic pancreatic cancer patients of any age who received GemCap, regardless of subsequent surgical therapy or radiotherapy. Patients treated with GemCap plus other chemotherapy or target therapy at the same time were excluded. Conference abstracts without full text and retrospective studies were either excluded. For multiple published articles that were identified reporting on the same clinical trial, the one with the most complete publication data was eligible. Any discrepancies were resolved by discussion. 


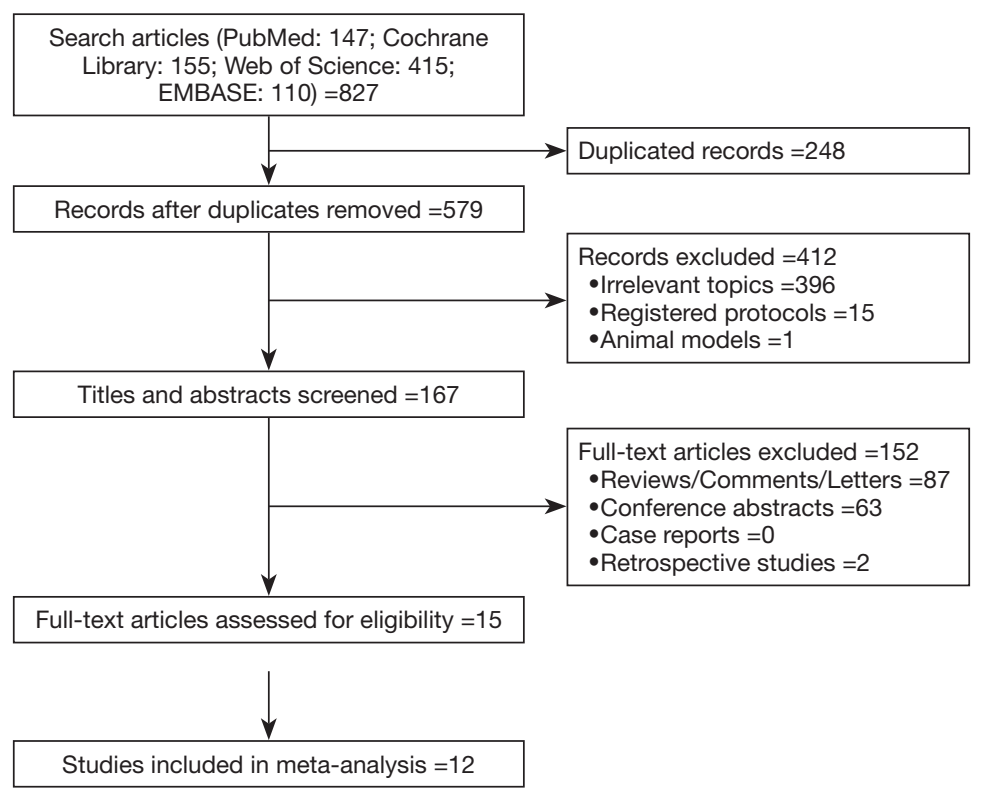

Figure 1 Flow chart of the relevant studies selection process.

\section{Data extraction and quality assessment}

The primary outcome was OS, and the second outcomes included PFS, 1-year survival rate, ORR, DCR, and adverse events. Two authors (BW and BX) independently extracted information from the full texts and supplementary materials. Any discrepancies were resolved by discussion. The following study details were collected from each eligible study: first author, year of publication, study design, number of patients, line of therapy, OS, PFS, 1-year survival rate, ORR, DCR, and adverse events. The methodological quality of each eligible study was evaluated by two authors (BW and BX) according to the Jadad scale (24-26).

\section{Statistical analysis}

Survival outcomes from randomized controlled trials were assessed by HR (OS and PFS)/OR (ORR and DCR) and 95\% CIs using RevMan version 5.3 software (Cochrane Collaboration's Information Management System). We tested for heterogeneity used $\mathrm{I}^{2}$. When $\mathrm{P} \geq 0.10$ and $\mathrm{I}^{2} \leq 50 \%$, the heterogeneity test showed no statistical significance. Thus, a fixed-effects model was used. Otherwise, a random-effects model was applied. $\mathrm{P}<0.05$ was considered statistically significant.

Pooled incidences of 1-year survival rate, ORR, DCR, and adverse events were done using STATA statistical software (version 14.0). The analyses were conducted in a Random-effects model. Potential publication bias was examined using Egger's test (27-29).

\section{Results}

\section{Study selection}

The initial search identified 827 relevant publications, of which 248 were duplicates; an additional 564 were excluded based on eligibility criteria, leaving 15 studies $(4,16,18,19,21,22,30-38)$ for further analysis (Figure 1).

\section{Study characteristics}

Study characteristics are presented in Table 1. Nine studies were multi-center clinical studies, two were single-center clinical studies, and the other three did not mention it. One study was a phase I study, one was a phase I/II study, eight were phase II studies, and the other five were randomized controlled phase III trials. Patients in 13 studies received firstline GemCap chemotherapy and in two studies were given second- or more-line GemCap chemotherapy. Using the Jadad score, nine studies were classified as low quality (a score of $\leq 2$ ), whereas six studies as high quality (a score of $\geq 3$ ).

\section{Effectiveness outcomes}

All studies reported an OS (Table 2). Three studies were 
Table 1 Characteristic of the eligible studies in the analysis

\begin{tabular}{|c|c|c|c|c|c|c|c|c|c|}
\hline Study & Year & $\begin{array}{l}\text { Single-/ } \\
\text { Multi- } \\
\text { center }\end{array}$ & Phase & $\begin{array}{l}\text { Line of } \\
\text { therapy }\end{array}$ & $\begin{array}{l}\text { No. } \\
\text { Patients }\end{array}$ & Age (years) & Chemotherapy & NCl-CTC & $\begin{array}{l}\text { Jadad } \\
\text { score }\end{array}$ \\
\hline Scheithauer & 2003 & Multi- & ॥ & First & 41 & 64 [40-75] & $\begin{array}{l}\text { Gem: } 2,200 \mathrm{mg} / \mathrm{m}^{2} \text {, day } 1 \text {; Cap: } 1,250 \mathrm{mg} / \mathrm{m}^{2} \text {, } \\
\text { twice daily, day } 1-7 \text {; every } 2 \text { weeks }\end{array}$ & NR & 3 \\
\hline Herrmann & 2007 & Multi- & III & First & 160 & NR & $\begin{array}{l}\text { Gem: } 1,000 \mathrm{mg} / \mathrm{m}^{2} \text {, day } 1,8 \text {; Cap: } 650 \mathrm{mg} / \mathrm{m}^{2} \text {, } \\
\text { twice daily, day } 1-14 \text {; every } 3 \text { weeks }\end{array}$ & 2.0 & 3 \\
\hline Park & 2007 & Single- & II & First & 45 & 55 [33-76] & $\begin{array}{l}\text { Gem: } 1,000 \mathrm{mg} / \mathrm{m}^{2} \text {, day } 1,8,15 \text {; Cap: } 830 \mathrm{mg} / \mathrm{m}^{2} \text {, } \\
\text { twice daily, day } 1-21 \text {; every } 4 \text { weeks }\end{array}$ & 3.0 & 1 \\
\hline Boeck & 2008 & Multi- & II & Second+ & 64 & 64 [47-75] & $\begin{array}{l}\text { Gem: } 1,000 \mathrm{mg} / \mathrm{m}^{2} \text {, day } 1,8 \text {; Cap: } 825 \mathrm{mg} / \mathrm{m}^{2} \text {, } \\
\text { twice daily, day } 1-14 \text {; every } 3 \text { weeks }\end{array}$ & 2.0 & 2 \\
\hline Cunningham & 2009 & Multi- & III & First & 267 & 62 [37-82] & $\begin{array}{l}\text { Gem: } 1,000 \mathrm{mg} / \mathrm{m}^{2} \text {, day } 1,8,15 \text {; Cap: } 830 \mathrm{mg} / \mathrm{m}^{2} \text {, } \\
\text { twice daily, day } 1-21 \text {; every } 4 \text { weeks }\end{array}$ & 2.0 & 3 \\
\hline Michael & 2009 & NR & 1 & First & 20 & 64 [41-80] & $\begin{array}{l}\text { Gem: } 20-50 \mathrm{mg} / \mathrm{m}^{2} \text {, day } 1 \text {, twice per week; Cap: } \\
800-2,000 \mathrm{mg} / \mathrm{m}^{2} \text {, twice daily, day } 1-5 \text {; each week }\end{array}$ & 2.0 & 1 \\
\hline Choi & 2012 & Single- & II & First & 50 & 53 [39-76] & $\begin{array}{l}\text { Gem: } 1,000 \mathrm{mg} / \mathrm{m}^{2} \text {, day } 1,8,15 \text {; Cap: } 830 \mathrm{mg} / \mathrm{m}^{2} \text {, } \\
\text { twice daily, day } 1-21 \text {; every } 4 \text { weeks }\end{array}$ & 3.0 & 1 \\
\hline Lee & 2012 & NR & II & First+ & 43 & 61 [42-76] & $\begin{array}{l}\text { Gem: } 1,250 \mathrm{mg} / \mathrm{m}^{2} \text {, day } 1,8 \text {; Cap: } 950 \mathrm{mg} / \mathrm{m}^{2} \text {, } \\
\text { twice daily, day } 1-14 \text {; every } 3 \text { weeks }\end{array}$ & 3.0 & 1 \\
\hline Quan & 2017 & NR & II & First & 16 & 71 [50-81] & $\begin{array}{l}\text { Gem: } 1,000 \mathrm{mg} / \mathrm{m}^{2} \text {, day } 1,8 \text {; Cap: } 650 \mathrm{mg} / \mathrm{m}^{2} \text {, } \\
\text { twice daily, day } 1-14 \text {; every } 3 \text { weeks }\end{array}$ & $\begin{array}{l}\text { CTCAE } \\
4.0\end{array}$ & 1 \\
\hline
\end{tabular}

Gem, gemcitabine; Cap, capecitabine; NCl-CTC, National Cancer Institute common toxicity criteria; CTCAE, Common Terminology Criteria for Adverse Events; NR, not reported.

excluded from survival analyses because these patients underwent a resection after GemCap $(35,37,38)$, which might potentially improve survival. Patients in two studies had been treated with radiotherapy $(33,38)$. Two studies did not report 1-year survival rates $(22,33)$. The median OS ranged from 6.4 to 11.2 months across studies. When patients underwent pancreaticoduodenectomy, the median OS ranged from 14.3 to 28.0 months. Data regarding OS from three studies were collected $(4,16,22)$, including
534 patients in the GemCap group and 532 patients in the Gem group. Forest plots showed that GemCap had a 15\% lower risk of death compared to Gem (HR: 0.85, 95\% CI: $0.75-0.95, \mathrm{P}=0.007$ ) (Figure 2). OS at 1 year was $32.0 \%$ (95\% CI: 28.1-35.9) (Figure 3). Publication bias was not observed in the result of Egger's test $(\mathrm{P}=0.185>0.05)$. The median PFS ranged from 3.9 to 6.5 months, much lower than that of patients who received pancreaticoduodenectomy (10 months). PFS data extracted from three studies were 
Table 2 Survival outcomes of the patients in the selected studies

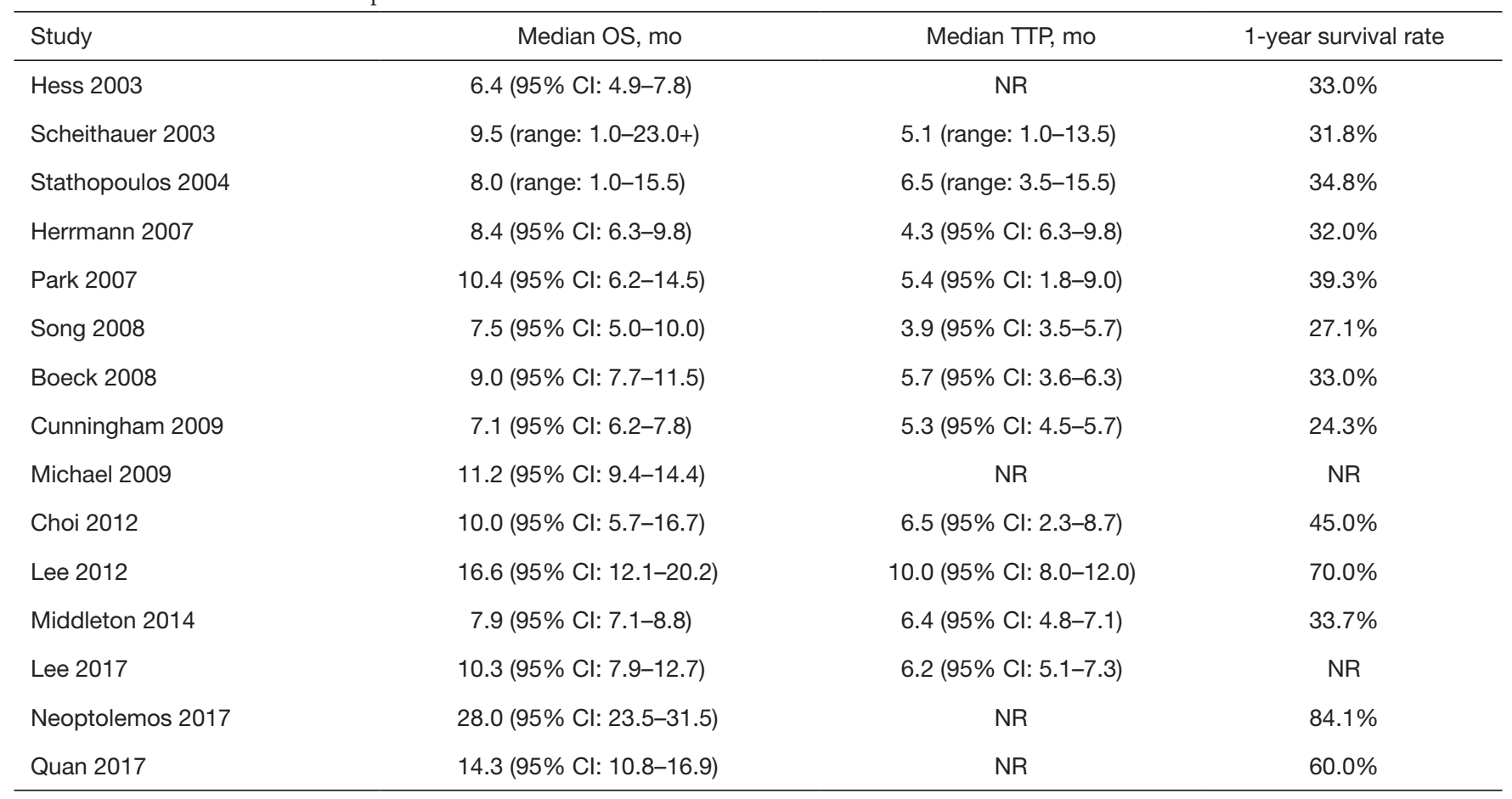

OS, overall survival; TTP, time to progression; NR, not reported.

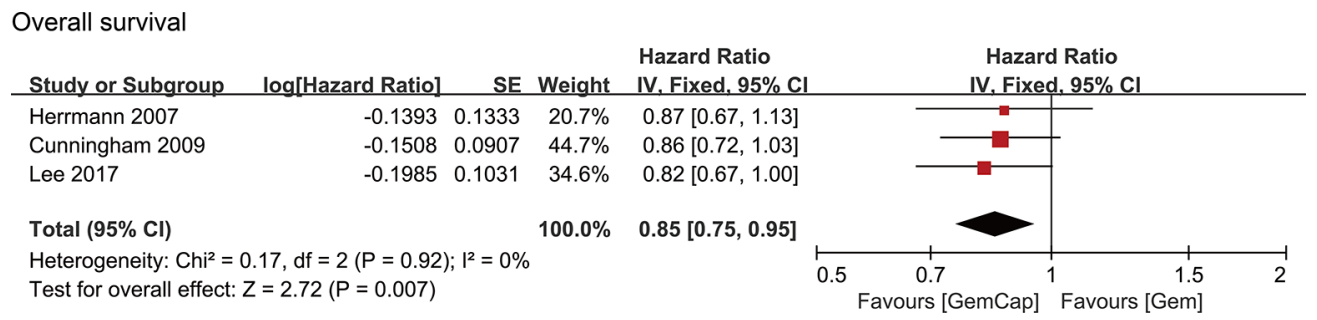

Figure 2 Forest plot of hazard ratios for overall survival in patients between GemCap group and Gem group. GemCap: gemcitabine plus capecitabine; GEM, gemcitabine alone; SE, standard error; IV, inverse variance statistical method; CI, confidence interval; I2, index of heterogeneity; Fix, fixed effect analysis model.

meta-analyzed $(4,16,22)$. Compared with Gem alone, GemCap showed a $20 \%$ lower risk of disease progression (HR: 0.80, 95\% CI: 0.72-0.90, $\mathrm{P}=0.0002$ ) (Figure 4).

Rate estimates of objective response (complete response and partial response) and disease control (complete response, partial response, and stable disease) were highly heterogeneous (respectively, $\mathrm{P}<0.001$ and $\mathrm{I}^{2}=79.4 \%$; $\mathrm{P}<0.001$ and $\left.\mathrm{I}^{2}=84.4 \%\right)$. For the whole study cohort, the estimated fraction of patients with objective response was 22.9\% (95\% CI: 17.6-28.3\%) (Figure 5); disease control was averaged to $65.7 \%$ (95\% CI: $56.7-74.8 \%$ ) (Figure 6). Egger's test did not show evidence of publication bias (ORR:
$\mathrm{P}=0.058>0.05$; DCR: $\mathrm{P}=0.226>0.05)$. In three phase III trials, in comparison with Gem, the pooled relative risk for complete response and partial response was significantly higher after combination therapy (OR: $1.98,95 \% \mathrm{CI}$ : 1.34-2.67, $\mathrm{P}=0.0003$ ) (Figure $7 A$ ). Two phase III trials were identified reporting disease control. GemCap showed significantly higher DCR compared to Gem alone (OR: 1.41, 95\% CI: $1.05-1.88, \mathrm{P}=0.02$ ) (Figure 7B).

\section{Toxicity}

In 11 studies, the adverse events were reported using the 
1-year survival rate

\begin{tabular}{|c|c|c|}
\hline Study & $\mathrm{R}(95 \% \mathrm{Cl})$ & Weight \% \\
\hline Hess 2003 & $0.33(0.18,0.48)$ & 5.22 \\
\hline Scheithauer 2003 & $0.32(0.18,0.46)$ & 5.87 \\
\hline Stathopoulos 2004 & $0.35(0.22,0.48)$ & 6.92 \\
\hline Herrmann 2007 & $0.32(0.25,0.39)$ & 14.32 \\
\hline Park 2007 & $0.39(0.25,0.53)$ & 5.89 \\
\hline Song 2008 & $0.27(0.16,0.38)$ & 8.72 \\
\hline Boeck 2008 & $0.33(0.21,0.45)$ & 8.13 \\
\hline Cunningham 2009 & $0.24(0.19,0.29)$ & 19.10 \\
\hline Choi 2012 & $0.45(0.31,0.59)$ & 6.20 \\
\hline Middleton 2014 & $0.34(0.29,0.39)$ & 19.64 \\
\hline Overall $(I-$ squared $=39.7 \%, p=0.093)$ & $0.32(0.28,0.36)$ & 100.00 \\
\hline Weights are from random effects analysis & & \\
\hline
\end{tabular}

Figure 3 Forest plot of the 1-year survival rates in patients treated with GemCap. R, rate.

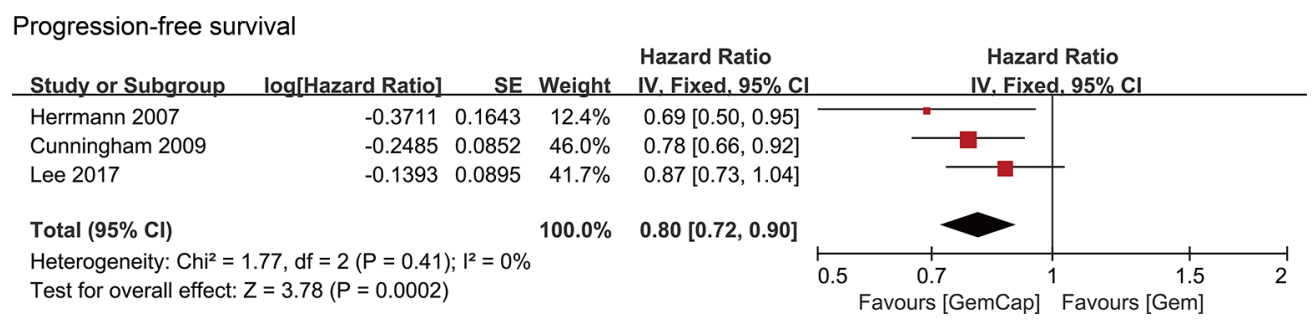

Figure 4 Forest plot of hazard ratios for progression-free survival in patients between GemCap group and Gem group.

\section{Objective response rate}

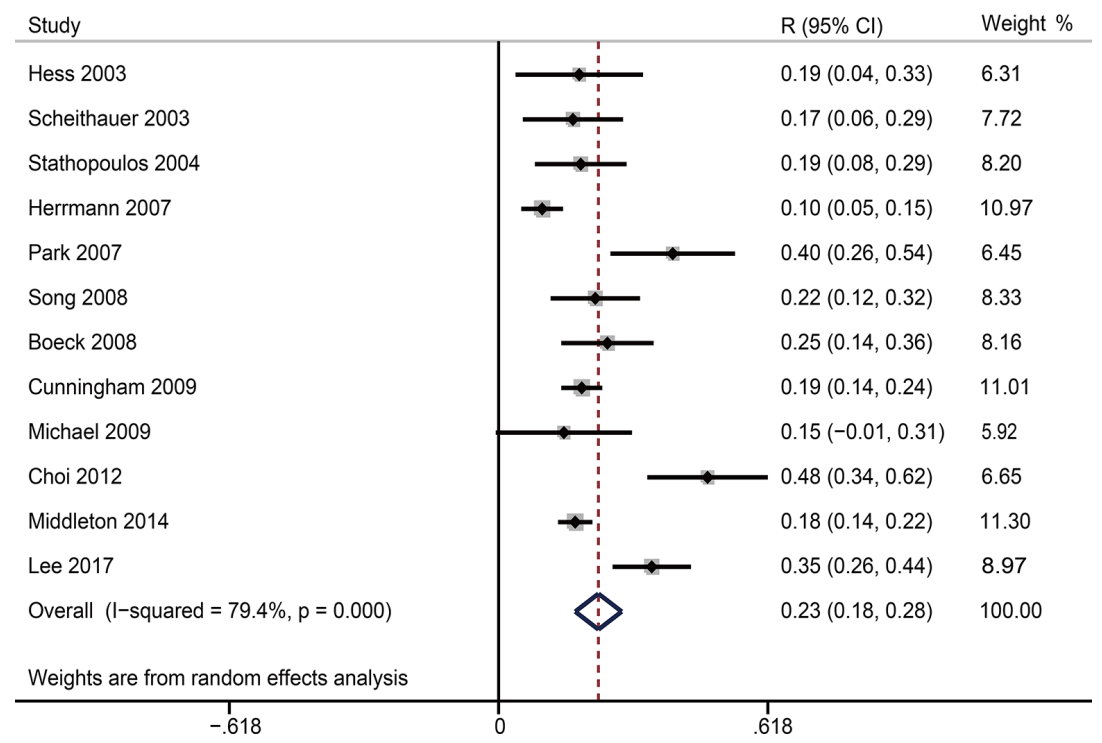

Figure 5 Forest plot of the objective response rates in patients treated with GemCap. 


\section{Disease control rate}

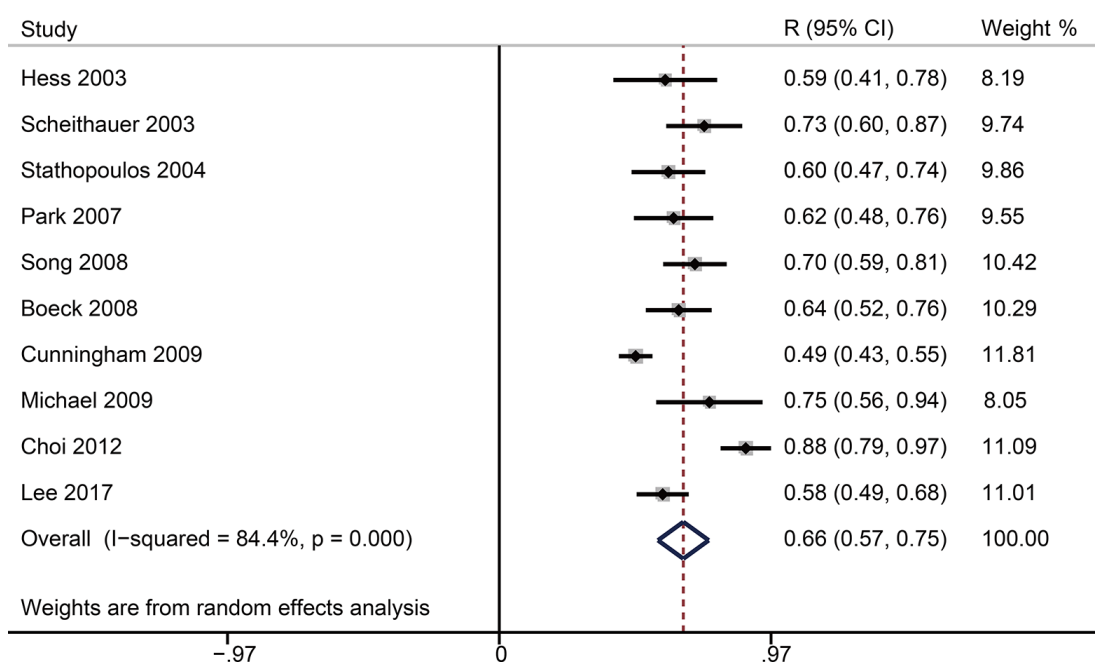

Figure 6 Forest plot of the disease control rates in patients treated with GemCap.

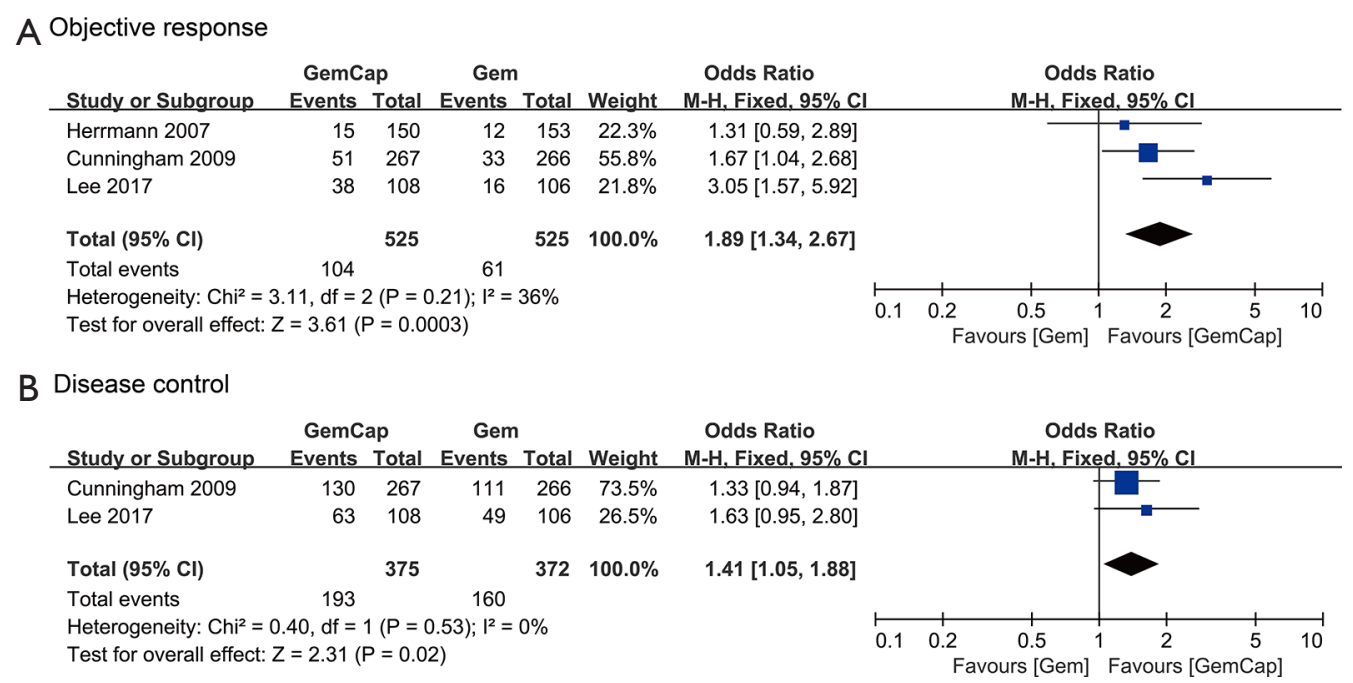

Figure 7 Forest plot of odds ratios for objective response (A) and disease control (B) in patients between GemCap group and Gem group.

National Cancer Institute common toxicity criteria (NCICTC) (version $2.0=5$; version $3.0=4$; version $4.0=2$ ). And only in one study, toxicities was reported using the Common Terminology Criteria for Adverse Events (CTCAE, 4.0). Three studies did not clearly describe the evaluation criteria that they used $(18,19,21)$. One death was reported by Stathopoulos in 2004 (21). The cause of death was upper gastrointestinal bleeding due to anticoagulant therapy of a deep venous thrombosis. One patient dead was reported by Herrmann in 2007 owing to several grade 4 adverse events (diarrhea, intrahepatic cholestasis, hyperbilirubinemia, and febrile infection) (16). There were four deaths reported by Middleton in 2014 (36) and four by Neoptolemos in 2017 (37) because of drug-related toxic effects. The pooled incidences of any-grade hematological adverse events were 41.9\% (95\% CI: 20.7-63.1\%) for anemia, 65.6\% (95\% CI: $56.4-74.8 \%$ ) for leucocytopenia, $42.2 \%$ (95\% CI: 28.0 $56.4 \%$ ) for neutropenia, and $31.7 \%$ (95\% CI: $21.6-41.7 \%$ ) for thrombocytopenia. The pooled incidences of any-grade non-hematological adverse events were $25.2 \%$ (95\% CI: 19.6-30.9\%) for hand-foot syndrome, $41.3 \%$ (95\% CI: 20.9-61.7\%) for nausea, 33.4\% (95\% CI: 29.2-37.6\%) for 
Table 3 Pooled analysis of any-grade adverse events.

\begin{tabular}{|c|c|c|}
\hline Toxicities & Incidence & $95 \% \mathrm{Cl}$ \\
\hline \multicolumn{3}{|l|}{ Hematological } \\
\hline Anemia & $41.9 \%$ & $20.7-63.1 \%$ \\
\hline Leucocytopenia & $65.6 \%$ & $56.4-74.8 \%$ \\
\hline Neutropenia & $42.2 \%$ & $28.0-56.4 \%$ \\
\hline Thrombocytopenia & $31.7 \%$ & $21.6-41.7 \%$ \\
\hline \multicolumn{3}{|l|}{ Non-hematological } \\
\hline Hand-foot syndrome & $25.2 \%$ & $19.6-30.9 \%$ \\
\hline Nausea & $41.3 \%$ & $20.9-61.7 \%$ \\
\hline Vomiting & $33.4 \%$ & $29.2-37.6 \%$ \\
\hline Fatigue & $38.2 \%$ & $5.7-70.7 \%$ \\
\hline Diarrhea & $34.8 \%$ & $30.8-38.7 \%$ \\
\hline Mucositis & $16.2 \%$ & $12.7-19.6 \%$ \\
\hline Constipation & $27.6 \%$ & $14.5-40.7 \%$ \\
\hline Alopecia & $24.1 \%$ & $6.5-41.7 \%$ \\
\hline
\end{tabular}

Table 4 Pooled analysis of grade $\geq 3$ adverse events.

\begin{tabular}{|c|c|c|}
\hline Toxicities & Incidence & $95 \% \mathrm{Cl}$ \\
\hline \multicolumn{3}{|l|}{ Hematological } \\
\hline Anemia & $4.9 \%$ & $3.1-6.6 \%$ \\
\hline Leucocytopenia & $7.9 \%$ & $3.1-12.6 \%$ \\
\hline Neutropenia & $19.7 \%$ & $12.8-26.7 \%$ \\
\hline Febrile neutropenia & $1.2 \%$ & $0-2.4 \%$ \\
\hline Thrombocytopenia & $4.7 \%$ & $2.3-7.0 \%$ \\
\hline \multicolumn{3}{|l|}{ Non-hematological } \\
\hline Hand-foot syndrome & $6.3 \%$ & $2.8-9.8 \%$ \\
\hline Nausea & $4.8 \%$ & $3.5-6.2 \%$ \\
\hline Vomiting & $4.6 \%$ & $3.3-6.0 \%$ \\
\hline Fatigue & $5.7 \%$ & $0.1-11.3 \%$ \\
\hline Diarrhea & $3.6 \%$ & $2.5-4.7 \%$ \\
\hline Mucositis & $2.0 \%$ & $0.7-3.3 \%$ \\
\hline Stomatitis & $2.7 \%$ & $1.1-4.3 \%$ \\
\hline Constipation & $2.8 \%$ & $0.5-5.1 \%$ \\
\hline
\end{tabular}

$\mathrm{Cl}$, confidence interval. vomiting, $38.2 \%$ (95\% CI: $5.7-70.7 \%$ ) for fatigue, $34.8 \%$ (95\% CI: 30.8-38.7\%) for diarrhea, $16.2 \%$ (95\% CI: $12.7-$ $19.6 \%$ ) for mucositis, $27.6 \%$ (95\% CI: $14.5-40.7 \%$ ) for constipation, and $24.1 \%$ (95\% CI: $6.5-41.7 \%$ ) for alopecia (Table 3). The pooled incidences of grade $\geq 3$ hematological adverse events were 4.9\% (95\% CI: 3.1-6.6\%) for anemia, 7.9\% (95\% CI: 3.1-12.6\%) for leucocytopenia, 19.7\% (95\% CI: $12.8-26.7 \%$ ) for neutropenia, $1.2 \%$ (95\% CI: 0-2.4\%), and $4.7 \%$ (95\% CI: $2.3-7.0 \%$ ) for thrombocytopenia. The pooled incidences of grade $\geq 3$ non-hematological adverse events were $6.3 \%$ (95\% CI: $2.8-9.8 \%$ ) for hand-foot syndrome, $4.8 \%$ (95\% CI: 3.5-6.2\%) for nausea, 4.6\% (95\% CI: $3.3-6.0 \%$ ) for vomiting, $5.7 \%$ (95\% CI: $0.1-11.3 \%$ ) for fatigue, 3.6\% (95\% CI: $2.5-4.7 \%$ ) for diarrhea, $2.0 \%$ (95\% CI: $0.7-3.3 \%$ ) for mucositis, $2.7 \%$ (95\% CI: $1.1-4.3 \%$ ) for stomatitis, and $2.8 \%$ (95\% CI: $0.5-5.1 \%)$ for constipation (Table 4).

\section{Discussion}

In our study, the addition of Cap to Gem showed a significant improved OS $(\mathrm{P}=0.007)$ and $\mathrm{PFS}(\mathrm{P}=0.0002)$ with no significant intertribal heterogeneity $\left(\mathrm{I}^{2}=0 \%\right.$, $\mathrm{P}>0.05$ ) compared with Gem alone. After GemCap therapy, $22.9 \%$ (95\% CI: 17.6-28.3\%) of patients achieved objective response and $65.7 \%$ (95\% CI: $56.7-74.8 \%$ ) of patients achieved disease control. About ten deaths were attributed to GemCap. A potential mechanism in explaining the results is that a Cap-induced decrease in cytidine deaminase activity could lead to the improvement of survival outcomes with GemCap therapy, but also interpret the toxicities associated with the combination treatment (39).

Previously, in a retrospective study (40), the OS was significantly improved with GemCap (12.1 months) compared to Gem (10.4 months) (HR: 0.52, 95\% CI: 0.28 $0.96, \mathrm{P}=0.037)$. Moreover, GemCap significantly reduced the hazard of disease progression compared with Gem monotherapy (HR: 0.46, 95\% CI: 0.27-0.79, P=0.035). The overall ORR of GemCap in Lim's study was $21.2 \%$, which was much higher than that of Gem (12.7\%). Neutropenia was the most common grade $\geq 3$ hematologic toxicity, but none of the patients had grade $\geq 3$ hand-foot syndrome in this study. Another retrospective study reported that median OS was 8.7 months (95\% CI: 6.7-10.7 months), 1-year survival rate after commencing GemCap was 34\% (95\% CI: $25-43 \%$ ), and incidence of grade $\geq 3$ hand-foot syndrome was approximately $8 \%$ (41). Notably, both trials above suggested GemCap as a more effective regimen than Gem 
monotherapy in the advanced or metastatic setting.

Adding capecitabine to standard gemcitabine reduced the hazard of death. Accordingly, phase I/II studies were conducted to determine the safety and efficacy of a firstline regimen combining Gem, Cap and oxaliplatin. Petrioli reported an ORR of $35.2 \%$ and a DCR of $79.4 \%$ in the treatment of combining all three drugs in advanced pancreatic cancer (42). Hess showed ORR in $41 \%$ of patients and DCR in $78 \%$ of patients (43). However, hematologic and non-hematologic toxicities were more severe with a combination of three-agent therapy in both studies.

The safety profile of gemcitabine and fluoropyrimidine is known to be non-overlapping, and combination therapy of these drugs is well tolerated. Furthermore, both drugs target the pyrimidine biosynthesis pathway and may, therefore, exert synergistically $(44,45)$. Another oral fluoropyrimidine, S-1, consists of tegafur, 5-chloro-2,4-dihydroxypyridine, and potassium oxonate at a molar ratio in 1:0.4:1, and inhibits dihydropyrimidine dehydrogenase. S-1 had proven efficacy in metastatic pancreatic cancer (46). An early phase II study of S-1 for metastatic pancreatic cancer reported a $21.1 \%$ partial response rate (47). Furthermore, two phase II studies of combined gemcitabine and S-1 in patients with advanced pancreatic cancer suggested that repeated 3-week cycles of combination chemotherapy with gemcitabine and S-1 were effective, convenient, and safe $(48,49)$. A recent metaanalysis of the addition of S-1 to Gem-based chemotherapy showed a statistically significant improvement in survival and suggested Gem plus S-1 as first-line chemotherapy for patients with advanced or metastatic pancreatic cancer (50).

Gem in combination with target agents is a new therapeutic modality. A meta-analysis reported that the ORR was $14.4 \%$ (95\% CI: 11.6-17.7\%), DCR was $55.0 \%$ (95\% CI: $51.5-58.5 \%$ ), and 1-year survival rate was $28.5 \%$ (95\% CI: $24.0-33.4 \%$ ) in patients treated with Gem plus erlotinib (51). These data suggested that Gem combined with target agents could be a first-line therapeutic option for advance or metastatic pancreatic cancer.

For patients with local advanced and inoperable pancreatic cancer, the potential for tumor down-staging with induction chemo-/radio-therapy is alluring to maximize the chance of complete resection. The results from Andriull et al. supported the claim: among 362 unresectable patients evaluated in 13 trials, 28\% (95\% CI: $21-35 \%)$ of patients were down-staged sufficiently to an objective response. However, the relatively low resection rate after preoperative therapy in this population of patients required very candid discussions with patients regarding the goal of therapy. Fortunately, 72\% (95\% CI: 59-86\%) of surgically explored patients underwent a successful pancreatic resection (52).

Treatment tolerability is strictly correlated with quality of life. GemCap was associated with worse hematologic and non-hematologic toxicities than Gem. Nonetheless, there was an improvement in the quality of life during treatment with the combination therapy regimen, suggesting the primary aim of an effective treatment in delaying the quality-of-life deterioration. In line with our findings, the GemCap plus oxaliplatin, despite the high incidence of treatment related toxicities, was able to increase the time to definitive deterioration of quality of life $(42,43)$. Bernhard et al. prospectively compared the quality of life in patients receiving GemCap versus Gem. In this phase III trial, in advanced pancreatic cancer, no difference in the quality of life was found between single-agent Gem and combination therapy (53). These studies indicated that an effective combination of chemotherapy could help maintain a good quality of life in patients with advanced pancreatic cancer.

\section{Limitations}

There were several limitations in the present study. First, there were only three randomized controlled trials included in the meta-analysis. Although no publication bias was shown in the single-arm analyses, heterogeneity across the trials might bias the results. Second, the dosages of GemCap were inconsistent and additional therapies (e.g., radiotherapy) had been added to the chemotherapy. Third, pooled analyses of Gem or Cap monotherapy were not comprised in this study as we mainly focused on the combination therapy. Future studies are needed to comprehensively compare the efficacy of gemcitabine plus capecitabine combination therapy, gemcitabine monotherapy, and capecitabine monotherapy.

In conclusion, this meta-analysis of advanced or metastatic pancreatic cancer patients treated with GemCap showed a favorable median OS, median PFS, 1-year survival rate, ORR, and DCR. The present study provided additional evidence for selecting GemCap as a superior chemotherapy regimen to Gem alone in the first-line treatment for advanced or metastatic pancreatic cancer.

\section{Acknowledgments}

We thank the Jian-Bin Wang and Wen-Qing Li in BiCheng Wang workgroup for their critical comments on the 
initial idea of the study.

Funding: This study was supported by the Independent Innovation Foundation of Wuhan Union Hospital (Grant number: 2019-109 to Bi-Cheng Wang).

\section{Footnote}

Conflicts of Interest: All authors have completed the ICMJE uniform disclosure form (available at http://dx.doi. org/10.21037/apm-20-45). The authors have no conflicts of interest to declare.

Ethical Statement: The authors are accountable for all aspects of the work in ensuring that questions related to the accuracy or integrity of any part of the work are appropriately investigated and resolved.

Open Access Statement: This is an Open Access article distributed in accordance with the Creative Commons Attribution-NonCommercial-NoDerivs 4.0 International License (CC BY-NC-ND 4.0), which permits the noncommercial replication and distribution of the article with the strict proviso that no changes or edits are made and the original work is properly cited (including links to both the formal publication through the relevant DOI and the license). See: https://creativecommons.org/licenses/by-nc-nd/4.0/.

\section{References}

1. Van Laethem JL, Verslype C, Iovanna JL, et al. New strategies and designs in pancreatic cancer research: consensus guidelines report from a European expert panel. Ann Oncol 2012;23:570-6.

2. Conroy T, Desseigne F, Ychou M, et al. FOLFIRINOX versus gemcitabine for metastatic pancreatic cancer. $\mathrm{N}$ Engl J Med 2011;364:1817-25.

3. Von Hoff DD, Ervin T, Arena FP, et al. Increased survival in pancreatic cancer with nab-paclitaxel plus gemcitabine. N Engl J Med 2013;369:1691-703.

4. Cunningham D, Chau I, Stocken DD, et al. Phase III randomized comparison of gemcitabine versus gemcitabine plus capecitabine in patients with advanced pancreatic cancer. J Clin Oncol 2009;27:5513-8.

5. Sultana A, Smith CT, Cunningham D, et al. Meta-analyses of chemotherapy for locally advanced and metastatic pancreatic cancer. J Clin Oncol 2007;25:2607-15.

6. Burris HA 3rd, Moore MJ, Andersen J, et al. Improvements in survival and clinical benefit with gemcitabine as first- line therapy for patients with advanced pancreas cancer: a randomized trial. J Clin Oncol 1997;15:2403-13.

7. Heinemann V, Haas M, Boeck S. Systemic treatment of advanced pancreatic cancer. Cancer Treat Rev 2012;38:843-53.

8. Springfeld C, Jaeger D, Buechler MW, et al. Chemotherapy for pancreatic cancer. Presse Med 2019;48:E159-74.

9. Louvet C, Labianca R, Hammel P, et al. Gemcitabine in combination with oxaliplatin compared with gemcitabine alone in locally advanced or metastatic pancreatic cancer: results of a GERCOR and GISCAD phase III trial. J Clin Oncol 2005;23:3509-16.

10. Poplin E, Feng Y, Berlin J, et al. Phase III, randomized study of gemcitabine and oxaliplatin versus gemcitabine (fixed-dose rate infusion) compared with gemcitabine (30-minute infusion) in patients with pancreatic carcinoma E6201: a trial of the Eastern Cooperative Oncology Group. J Clin Oncol 2009;27:3778-85.

11. Ryan DP, Hong TS, Bardeesy N. Pancreatic adenocarcinoma. N Engl J Med 2014;371:1039-49.

12. Tempero MA, Malafa MP, Behrman SW, et al. Pancreatic adenocarcinoma, version 2.2014: featured updates to the NCCN guidelines. J Natl Compr Canc Netw 2014;12:1083-93.

13. Chiorean EG, Cheung WY, Giordano G, et al. Realworld comparative effectiveness of nab-paclitaxel plus gemcitabine versus FOLFIRINOX in advanced pancreatic cancer: a systematic review. Ther Adv Med Oncol 2019;11:1758835919850367.

14. Ishikawa T, Utoh M, Sawada N, et al. Tumor selective delivery of 5 -fluorouracil by capecitabine, a new oral fluoropyrimidine carbamate, in human cancer xenografts. Biochem Pharmacol 1998;55:1091-7.

15. Miwa M, Ura M, Nishida M, et al. Design of a novel oral fluoropyrimidine carbamate, capecitabine, which generates 5 -fluorouracil selectively in tumours by enzymes concentrated in human liver and cancer tissue. Eur J Cancer 1998;34:1274-81.

16. Herrmann R, Bodoky G, Ruhstaller T, et al. Gemcitabine plus capecitabine compared with gemcitabine alone in advanced pancreatic cancer: a randomized, multicenter, phase III trial of the Swiss Group for Clinical Cancer Research and the Central European Cooperative Oncology Group. J Clin Oncol 2007;25:2212-7.

17. Cartwright TH, Cohn A, Varkey JA, et al. Phase II study of oral capecitabine in patients with advanced or metastatic pancreatic cancer. J Clin Oncol 2002;20:160-4. 
18. Hess V, Salzberg M, Borner M, et al. Combining capecitabine and gemcitabine in patients with advanced pancreatic carcinoma: a phase I/II trial. J Clin Oncol 2003;21:66-8.

19. Scheithauer W, Schüll B, Ulrich-Pur H, et al. Biweekly high-dose gemcitabine alone or in combination with capecitabine in patients with metastatic pancreatic adenocarcinoma: a randomized phase II trial. Ann Oncol 2003;14:97-104.

20. Schilsky RL, Bertucci D, Vogelzang NJ, et al. Doseescalating study of capecitabine plus gemcitabine combination therapy in patients with advanced cancer. J Clin Oncol 2002;20:582-7.

21. Stathopoulos GP, Syrigos K, Polyzos A, et al. Frontline treatment of inoperable or metastatic pancreatic cancer with gemcitabine and capecitabine: an intergroup, multicenter, phase II study. Ann Oncol 2004;15:224-9.

22. Lee HS, Chung MJ, Park JY, et al. A randomized, multicenter, phase III study of gemcitabine combined with capecitabine versus gemcitabine alone as first-line chemotherapy for advanced pancreatic cancer in South Korea. Medicine (Baltimore) 2017;96:e5702.

23. Moher D, Liberati A, Tetzlaff J, et al. Preferred reporting items for systematic reviews and meta-analyses: the PRISMA Statement. Open Med 2009;3:e123-30.

24. Jadad AR, Moore RA, Carroll D, et al. Assessing the quality of reports of randomized clinical trials: is blinding necessary? Control Clin Trials 1996;17:1-12.

25. OuYang PY, Zhang XM, Qiu XS, et al. A Pairwise MetaAnalysis of Induction Chemotherapy in Nasopharyngeal Carcinoma. Oncologist 2019;24:505-12.

26. Ramamoorthi R, Gahreman D, Skinner T, et al. The effect of yoga practice on glycemic control and other health parameters in the prediabetic state: A systematic review and meta-analysis. PLoS One 2019;14:e0221067.

27. Egger M, Davey Smith G, Schneider M, et al. Bias in meta-analysis detected by a simple, graphical test. BMJ 1997;315:629-34.

28. Wang BC, Cao RB, Li PD, et al. The effects and safety of PD-1/PD-L1 inhibitors on head and neck cancer: A systematic review and meta-analysis. Cancer Med 2019;8:5969-78.

29. Ding W, Tan Y, Qian Y, et al. Clinicopathologic and prognostic significance of tumor-associated macrophages in patients with hepatocellular carcinoma: A meta-analysis. PLoS One 2019;14:e0223971.

30. Park BB, Park JO, Lee HR, et al. A phase II trial of gemcitabine plus capecitabine for patients with advanced pancreatic adenocarcinoma. Cancer Chemother Pharmacol 2007;60:489-94.

31. Boeck S, Hoehler T, Seipelt G, et al. Capecitabine plus oxaliplatin (CapOx) versus capecitabine plus gemcitabine (CapGem) versus gemcitabine plus oxaliplatin (mGemOx): final results of a multicenter randomized phase II trial in advanced pancreatic cancer. Ann Oncol 2008;19:340-7.

32. Song HS, Do YR, Chang HM, et al. A phase II study of capecitabine plus gemcitabine in patients with locally advanced or metastatic pancreatic cancer. Cancer Chemother Pharmacol 2008;62:763-8.

33. Michael M, Price T, Ngan SY, et al. A phase I trial of Capecitabine plus Gemcitabine with radical radiation for locally advanced pancreatic cancer. Br J Cancer 2009;100:37-43.

34. Choi JG, Seo JH, Oh SC, et al. A Phase II Trial of Gemcitabine plus Capecitabine for Patients with Advanced Pancreatic Cancer. Cancer Res Treat 2012;44:127-32.

35. Lee J-L, Kim SC, Kim J-H, et al. Prospective efficacy and safety study of neoadjuvant gemcitabine with capecitabine combination chemotherapy for borderline-resectable or unresectable locally advanced pancreatic adenocarcinoma. Surgery 2012;152:851-62.

36. Middleton G, Silcocks P, Cox T, et al. Gemcitabine and capecitabine with or without telomerase peptide vaccine GV1001 in patients with locally advanced or metastatic pancreatic cancer (TeloVac): an open-label, randomised, phase 3 trial. Lancet Oncol 2014;15:829-40.

37. Neoptolemos JP, Palmer DH, Ghaneh P, et al. Comparison of adjuvant gemcitabine and capecitabine with gemcitabine monotherapy in patients with resected pancreatic cancer (ESPAC-4): a multicentre, open-label, randomised, phase 3 trial. Lancet 2017;389:1011-24.

38. Quan K, Sutera P, Xu K, et al. Results of a prospective phase 2 clinical trial of induction gemcitabine/capecitabine followed by stereotactic ablative radiation therapy in borderline resectable or locally advanced pancreatic adenocarcinoma. Pract Radiat Oncol 2018;8:95-106.

39. Courtin A, Richards FM, Bapiro TE, et al. Anti-Tumour Efficacy of Capecitabine in a Genetically Engineered Mouse Model of Pancreatic Cancer. PLoS One 2013;8:e67330.

40. Lim JY, Cho JH, Lee SJ, et al. Gemcitabine Combined with Capecitabine Compared to Gemcitabine with or without Erlotinib as First-Line Chemotherapy in Patients with Advanced Pancreatic Cancer. Cancer Res Treat 2015;47:266-73.

41. Hubner RA, Worsnop F, Cunningham D, et al. 
Gemcitabine plus capecitabine in unselected patients with advanced pancreatic cancer. Pancreas 2013;42:511-5.

42. Petrioli R, Roviello G, Fiaschi AI, et al. Gemcitabine, oxaliplatin, and capecitabine (GEMOXEL) compared with gemcitabine alone in metastatic pancreatic cancer: a randomized phase II study. Cancer Chemother Pharmacol 2015;75:683-90.

43. Hess V, Pratsch S, Potthast S, et al. Combining gemcitabine, oxaliplatin and capecitabine (GEMOXEL) for patients with advanced pancreatic carcinoma (APC): a phase I/II trial. Ann Oncol 2010;21:2390-5.

44. Ren Q, Kao V, Grem JL. Cytotoxicity and DNA fragmentation associated with sequential gemcitabine and 5-fluoro-2'-deoxyuridine in HT-29 colon cancer cells. Clin Cancer Res 1998;4:2811-8.

45. Hidalgo M, Castellano D, Paz-Ares L, et al. Phase I-II study of gemcitabine and fluorouracil as a continuous infusion in patients with pancreatic cancer. J Clin Oncol 1999;17:585-92.

46. Okusaka T, Funakoshi A, Furuse J, et al. A late phase II study of S-1 for metastatic pancreatic cancer. Cancer Chemother Pharmacol 2008;61:615-21.

47. Ueno H, Okusaka T, Ikeda M, et al. An early phase II study of S-1 in patients with metastatic pancreatic cancer. Oncology 2005;68:171-8.

48. Oh DY, Cha Y, Choi IS, et al. A multicenter phase II

Cite this article as: Xiao BY, Wang BC, Lin GH, Li PC. Efficacy and safety of gemcitabine plus capecitabine in the treatment of advanced or metastatic pancreatic cancer: a systematic review and meta-analysis. Ann Palliat Med 2020;9(4):1631-1642. doi: 10.21037/apm-20-45 study of gemcitabine and S-1 combination chemotherapy in patients with unresectable pancreatic cancer. Cancer Chemother Pharmacol 2010;65:527-36.

49. Song H, Han B, Park CK, et al. Phase II trial of gemcitabine and S-1 for patients with advanced pancreatic cancer. Cancer Chemother Pharmacol 2013;72:845-52.

50. Liu Y, Huang QK, Hong WD, et al. The addition of S-1 to gemcitabine-based chemotherapy improves survival with increased toxicity for patients with advanced pancreatic cancer: combined meta-analysis of efficacy and safety profile. Clin Res Hepatol Gastroenterol 2015;39:254-60.

51. Wang Y, Hu GF, Zhang QQ, et al. Efficacy and safety of gemcitabine plus erlotinib for locally advanced or metastatic pancreatic cancer: a systematic review and metaanalysis. Drug Des Devel Ther 2016;10:1961-72.

52. Andriulli A, Festa V, Botteri E, et al. Neoadjuvant/ preoperative gemcitabine for patients with localized pancreatic cancer: a meta-analysis of prospective studies. Ann Surg Oncol 2012;19:1644-62.

53. Bernhard J, Dietrich D, Scheithauer W, et al. Clinical benefit and quality of life in patients with advanced pancreatic cancer receiving gemcitabine plus capecitabine versus gemcitabine alone: A randomized multicenter phase III clinical trial - SAKK 44/00-CECOG/PAN.1.3.001. J Clin Oncol 2008;26:3695-701. 